\title{
Visualizing the Effect of Built Environment on COVID-19 Transmission: A Community-Level Study in Wuhan, China
}

\section{ISSN: 2578-0336}

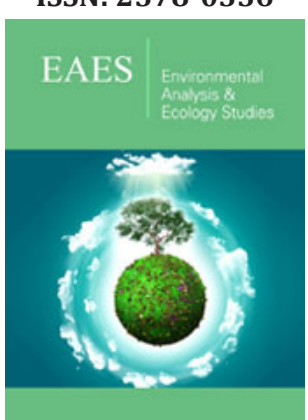

*Corresponding author: Siqin WANG, School of Earth and Environmental Sciences, University of Queensland, Chamberlain Building, Brisbane, Room 542, 4067, Australia

Submission: 制 January 22, 2021

Published: April 28, 2021

Volume 8 - Issue 3

How to cite this article: Siqin WANG, Zhe GAO, Jiang GU. Visualizing the Effect of Built Environment on COVID-19 Transmission: A Community-Level Study in Wuhan, China. Environ Anal Eco stud. 8(3). EAES. 000687. 2021.

DOI: 10.31031/EAES.2021.08.000687

Copyright@ Siqin WANG, This article is distributed under the terms of the Creative Commons Attribution 4.0 International License, which permits unrestricted use and redistribution provided that the original author and source are credited.

\author{
Siqin WANG ${ }^{1 *}$, Zhe $\mathrm{GAO}^{2}$ and Jiang $\mathrm{GU}^{3}$ \\ ${ }^{1}$ Post-Doc Research Fellow, University of Queensland, Australia \\ ${ }^{2}$ Lecturer, Central China Normal University, China \\ ${ }^{3}$ Associate Professor, Central China Normal University, China
}

\begin{abstract}
With the outbreak of a novel respiratory coronavirus disease (COVID-19) over the world, restriction of human mobility plays an important role to reduce the potential for the spread of virus. People are restricted for limited activities in local communities where the built environment in communities serve as a mediated pathway for the virus transmission. Our study aims to examine to what extent built environment factors explain COVID-19 transmission at the community level. Drawing on primary data collected from 648 communities in Wuhan, China, we employed a geographically weighted regression and a 3D mapping approach to examine the relationship between COVID-19 confirmed cases and three built environment factors including green coverage, property price, and underground parking. We find that green coverage and property price explain COVID-19 transmission better in communities with a larger amount of confirmed cases.
\end{abstract}

Keywords: COVID-19 transmission; Built environment; 3D visualization; Geographically weighted regression; Wuhan

\section{Introduction}

A novel coronavirus disease, called COVID-19 by the World Health Organization (WHO) [1], was monitored and reported in December 2019 by Chinese health authorities. The outbreak of COVID-19 has spread across China and infected 72,436 Chinese of which 1,868 have died by February $17^{\text {th }}$ (NHCPRC, 2020) [2]. On March $11^{\text {th }}$ when WHO announced COVID-19 outbreak as a pandemic (WHO, 2020), the confirmed COVID-19 cases have been adding up to 118,000 in 114 countries and causing 4,291 deaths. As a respiratory disease, the fundamental interventions of COVID-19 transmission is to restrict human mobility and keep social distances, which have been adopted by government in various countries to shut down local communities and enforce residents to stay at home with exceptions of limited outdoor activities in local neighbourhoods [3].

Under this circumstance, the Built Environment (BE) at the community level serves as an important mediated pathway to reduce the local spread and transmission of COVID-19 within a community. Studies have recognized that BE factors have the great potential to prevent infectious spread by affecting connectance and exposure of people to common space and configurations [4], such as street walkability, green coverage and housing density that have been widely studied as parts of the theorized 3D factors (design, density, and diversity) [5]. Such examinations of BE factors are particularly important to lockdown cities like Wuhan, the capital city of Hubei Province in Central China where the earliest closure policy was implemented, and citizens have been strictly restricted in their local communities (Xiaoqu1 in Chinese) since January $23^{\text {rd }}$, 2020. Herein, the primary interest of our study is to what extent BE factors explain COVID-19 transmission at the community level after the lockdown policy. Driven by this curiosity, we select three BE factors to test out if they are associated with COVID-19 confirmed cases and then employ a 3D mapping approach to visualize how differently these three factors affect COVID-19 cases in Wuhan, China. 


\section{Data and Method}

As a novel study at the community level, we collect primary data across 648 communities in Wuhan 387 or $60 \%$ of them located in main urban areas 2 containing three towns Hankou, Hanyang and Wuchang), including the confirmed cases of COVID-19 by $\mathrm{Feb} 17^{\text {th }}$ posted in community announcement boards, the number of households, the percentage of green space, the number of underground parking lots, and property prices on the current market in each community from AnJuKe3. The total confirmed cases in these 648 communities are 6491 , accounting for $15.18 \%$ of the total in Wuhan (42752) by Feb $17^{\text {th }}[2]$.

We then select green coverage, underground parking, property price to represent the effect of BE due to the following reasons. Considering the possible environmentally mediated transmission of COVID-19, green coverage and underground parking are selected from the spatial perspective to reflect social distancing and the likelihood of exposure to virus in ground and underground space; property price serves as a reflection of community profile and administration from a socioeconomic perspective given that communities with higher property prices are more likely to be recently developed, better managed, and better equipped with hygienic facilities (e.g. waste transfer), thus hypothesized to have less COVID-19 cases.

Methodologically, we conduct two sets of regression analyses, an Ordinary Least Square (OLS) regression and a Geographically
Weighted Regression (GWR) (more technical details found in Fotheringham et al. [6]. OLS is a global analysis to indicate the association between COVID-19 confirmed cases (normalized by the number of total households in that community) and the three selected BE factors. Then GWR is followed as a local analysis to reveal to what extent three selected BE factors affect COVID-19 cases, reflected as the Standardized Residuals (SR) produced by GWR. The smaller a SR is, the better a BE factor explains COVID-19 cases. The values of SR are further categorized to the associative level of high $(<0.5)$, medium $(0.5$ to 1.5$)$, and low $(>1.5)$ which are mapped out horizontally in a $3 \mathrm{D}$ visualization, coupling with the confirmed COVID-19 cases heightened vertically.

\section{Result}

To start with, the OLS result shows that green coverage and underground parking are negatively $(\mathrm{p}<0.05)$ but property price is positively $(\mathrm{p}<0.05)$ associated with COVID-19. Based on this statistical result, we give particular attentions to communities where BE factors are highly associated (red columns in Figure 1). For property price and green coverage, red columns (a high level of association) are dispersal across the whole study area but ones with extreme heights are concentrated within the $5 \mathrm{~km}$ to Huanan Seafood Market where the first wave of COVID-19 cases appeared in early Dec, 2019. Conversely, red columns mapped in underground parking have relatively lower heights, located beyond $5 \mathrm{~km}$ to Huanan Seafood Market while the blue columns (a low level of association) are concentrated within the $5 \mathrm{~km}$-distance.

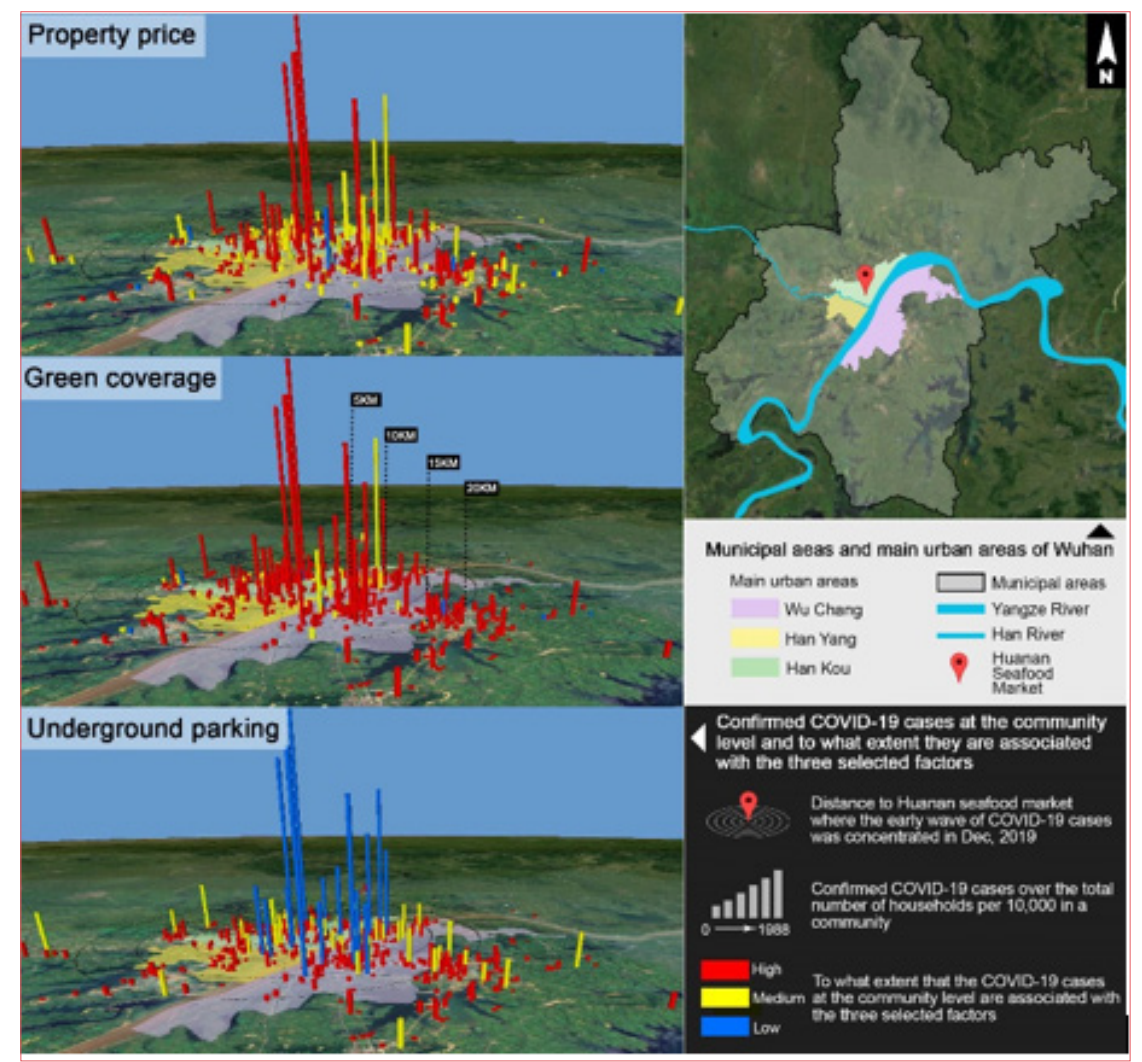

Figure 1: Prevalence of COVID-19 cases and to what extent that COVID-19 cases are associated with the selected built environment factors at the community level in Wuhan, China 
In other words, property price and green coverage are highly associated with COVID-19 in communities observed with a large amount of confirmed cases; while underground parking is better associated with communities with less confirmed cases. In concert with the findings revealed by OLS, we further find that larger green coverage reduces the likelihood of COVID-19 transmission, perhaps by offering more outdoor space and facilitating social distancing, whereas less underground parking lots create more compact indoor space, increasing the possibilities of COVID-19 transmission. It is worth noting that communities with higher property prices are observed with and predicted to have a large amount of COVID-19 cases, which runs counter to our preceding hypothesis. The possible explanation may be that more expensive communities in Wuhan are more likely to be recently developed with compact environmental design, being high in plot ratio and dense in housing and population, which facilitates the COVID-19 transmission.

\section{Conclusion}

As an initiate attempt, the key contribution of this study is to contribute a community-level study examining the effect of built environment on COVID-19 transmission by a geographically weighted regression and a 3D visualization. We find that green coverage and property price are associated with COVID-19 transmission in communities observed with a large amount of confirmed cases, which are hardly revealed by data at the subdistrict (jiedao) and above-district levels [6].

\section{Note:}

1. The concept of 'community' used in our study refers to Xiaoqu in Chinese, similar to the concept of housing estates in the western context in terms of the spatial scale and the number of households. In the Chinese administrative structure, Xiaoqus constitute a community (Shequ in Chinese) and communities constitute a sub-district (Jiedao in Chinese) which is the smallest spatial unit of Census.
2. The three towns are separated by Yangze River and Han River. In terms of political subdivisions, Hankou is composed by District of Jianghan, Jiang'an, and Qiaokou; Hanyang is composed by District of Hanyang; Wuchang is composed by District of Wuchang, Hongshan, and Qingshan.

3. A Chinese real estate website: https://wuhan.anjuke.com

Software: ArcMap 10.7.1, ArcGlobe 10.7.1, Photoshop CC 2017.

\section{Declaration of Conflicting Interests}

The author(s) declared no potential conflicts of interest with respect to the research, authorship, and/or publication of this article.

\section{Funding}

The author(s) received no financial support for the research, authorship, and/or publication of this article.

\section{References}

1. World Health Organization (2020) Coronavirus disease 2019 (COVID-19) Situation Report 67. https://apps.who.int/iris/bitstream/ handle/10665/331613/nCoVsitrep27Mar2020-eng.pdf

2. NHCPRC (National Health Commission of the People's Republic of China) (2020) COVID-19 Report.

3. Zhang L, Liu Y (2020) Potential interventions for novel coronavirus in China: A Systematic Review. J Med Virol 92(5): 479-490.

4. Dietz L, Horve PF, Coil D, Fretz M, Van Den Wymelenberg K (2020) 2019 Novel Coronavirus (COVID-19) Outbreak: A Review of the Current Literature and Built Environment (BE) Considerations to Reduce Transmission. pp. 1-13.

5. Cervero R, Kockelman K (1997) Travel demand and the 3Ds: Density, diversity, and design. Transportation research. Part D, Transport and Environment 2(3): 199-219.

6. Fotheringham AS, Brunsdon C, Charlton M (2003) Geographically weighted regression: the analysis of spatially varying relationships. John Wiley \& Sons, p. 284.

For possible submissions Click below: 